ERSpublications

A single positive Pseudomonas aeruginosa sputum culture is not associated with increased longterm mortality in COPD http://ow.ly/x5wvD

Afroditi K. Boutou ${ }^{1}$, Yogini Raste ${ }^{1}$, Jeremy Reid ${ }^{1}$, Khalid Alshafi ${ }^{2}$, Michael I. Polkey ${ }^{1}$ and Nicholas S. Hopkinson ${ }^{1}$ ${ }^{1}$ NIHR Respiratory Biomedical Research Unit, Royal Brompton and Harefield NHS Foundation Trust and Imperial College, London, UK. ${ }^{2}$ Dept of Microbiology, Royal Brompton Hospital, London, UK.

Correspondence: Afroditi K. Boutou, 9-13, Stratigou Sarafi Str, Kalamaria, 55132 Thessaloniki, Greece.

E-mail: afboutou@yahoo.com

Received: Dec 102013 | Accepted after revision: May 132014 | First published online: July 172014

Support statement: This study was supported by the NIHR Respiratory Biomedical Research Unit (Royal Brompton and Harefield NHS Foundation Trust and Imperial College, London, UK).

Conflict of interest: None declared.

\title{
References
}

1 Kelly JL, Bamsey O, Smith C, et al. Health status assessment in routine clinical practice: the chronic obstructive pulmonary disease assessment test score in outpatients. Respiration 2012; 84: 193-199.

2 Wilson R, Sethi S, Anzueto A, et al. Antibiotics for treatment and prevention of exacerbations of chronic obstructive pulmonary disease. J Infect 2013; 67: 497-515.

3 Pressler T, Bohmova C, Conway S, et al. Chronic Pseudomonas aeruginosa infection definition: EuroCareCF Working Group report. J Cyst Fibros 2011; 10: Suppl. 2, S75-S78.

4 Loebinger MR, Wells AU, Hansell DM, et al. Mortality in bronchiectasis: a long-term study assessing the factors influencing survival. Eur Respir J 2009; 34: 843-849.

5 Almagro P, Salvadó M, Garcia-Vidal C, et al. Pseudomonas aeruginosa and mortality after hospital admission for chronic obstructive pulmonary disease. Respiration 2012; 84: 36-43.

6 Lin SH, Kuo PH, Hsueh PR, et al. Sputum bacteriology in hospitalized patients with acute exacerbation of chronic obstructive pulmonary disease in Taiwan with an emphasis on Klebsiella pneumoniae and Pseudomonas aeruginosa. Respirology 2007; 12: 81-87.

7 Montero M, Domínguez M, Orozco-Levi M, et al. Mortality of COPD patients infected with multi-resistant Pseudomonas aeruginosa: a case and control study. Infection 2009; 37: 16-19.

8 Murphy TF. The many faces of Pseudomonas aeruginosa in chronic obstructive pulmonary disease. Clin Infect Dis 2008; 1534-1535.

9 Renom F, Yáñez A, Garau M, et al. Prognosis of COPD patients requiring frequent hospitalization: role of airway infection. Respir Med 2010; 104: 840-848.

10 Boutou AK, Shrikrishna D, Tanner RJ, et al. Lung function indices for predicting mortality in COPD. Eur Respir J 2013; 42: 616-625.

\section{Does traffic noise influence respiratory mortality?}

\author{
To the Editor:
}

Over the last decade, several studies have investigated the association between noise levels, primarily due to road traffic in large cities, and pathologies not related to either traditional hearing impairments or sleep disorders. These pathologies are mainly hypertension and cardiovascular, connective system and respiratory diseases [1]. Their impact on public health has been assessed in time series studies, indicating a traffic noise effect on both cardiovascular and respiratory hospital admissions rates similar to that attributed to air pollutants [2]. In addition, a recent study has shown an association of noise levels with cardiovascular mortality [3]. The description of the physiopathological mechanisms involved in this association reveal an actual impact of current road traffic noise levels on health [1]. Others question this because of the high correlation between traffic noise and air pollution [4], although a previous study in our setting showed an independent association between noise and cardiovascular mortality from the effect of the primary chemical air pollutants [5]. However, the effect of noise on respiratory mortality has not yet been investigated.

In this study, we examined the association between daily mortality due to respiratory causes (International Classification of Diseases, 9th revision, codes 460-519) and daytime noise levels in the city of Madrid 


\begin{tabular}{ccc} 
& \multicolumn{2}{c}{ Age years } \\
\cline { 2 - 3 } & $<65$ & $\geqslant 65$ \\
\hline Diurnal noise at lag 0 & $-1.4(-23.4-20.5)$ & $4.8(-0.7-10.4)^{\#}$ \\
$\quad$ Lag 1 & $-5.3(-27.5-16.7)$ & $6.5(0.8-12.2)^{*}$ \\
Lag 2 & $2.4(-20.0-24.0)$ & $-5.2(-10.8-5.1)$ \\
Lag 3 & $-4.0(-26.0-17.9)$ & $-2.2(-7.9-32.9)$ \\
Diurnal noise at lag 1 & & $6.1(0.2-12.0)^{*}$ \\
$\quad$ Adjustment for $\mathrm{PM}_{2.5}$ & $-6.4(-29.3-16.5)$ & $6.2(0.6-11.9)^{*}$ \\
$\quad$ Adjustment for $\mathrm{NO}_{2}$ & $-5.1(-27.2-17.1)$ &
\end{tabular}

Data are presented as percentage increase in risk (95\% CI). PM2.5: particulate matter with aerodynamic diameter $<2.5 \mu \mathrm{m} .{ }^{*}: \mathrm{p}<0.1 .^{*}: \mathrm{p}<0.05$.

(Spain), from January 1, 2003 to December 31, 2005, using a time-stratified case-crossover design. We used overdispersed Poisson regression adjusting for temperature, with natural cubic splines with four degrees of freedom for averaged lags $0-1$ and 2-6, dummy variables for public holidays and influenza epidemics, and the three-way interaction between day of the week, month and year to control for seasonality and time trends [6]. We examined short-term effects up to 3 days lag. Moreover, we provided evidence of an air pollution-independent association [7] after adjusting the results for primary chemical air pollutants (particulate matter with aerodynamic diameter $<2.5 \mu \mathrm{m}(\mathrm{PM} 2.5)$ and nitrogen dioxide) at the same lag as noise levels. Daily mortality was obtained from the Madrid Regional Inland Revenue Department, which is the department responsible for mortality registry. Diurnal equivalent noise levels (during the 08:00-22:00 h period) were provided by six of the urban background stations of the Madrid Municipal Automatic Air Pollution Monitoring Network that also measures real-time noise pollution levels, while air pollution data were supplied by all 24 monitoring stations.

The average daytime noise level in Madrid was $65 \mathrm{~dB}(\mathrm{~A})$, ranging from 62.1 to $71.0 \mathrm{~dB}(\mathrm{~A})$. The average daily death rate due to respiratory causes was 9.5 , ranging from 0 to 32 , with $>90 \%$ of deaths in those aged $\geqslant 65$ years. Noise levels showed low correlation with chemical air pollutants $(r=0.28$ and $r=0.01$ for nitrogen dioxide and PM2.5, respectively). The strongest and statistically significant $(\mathrm{p}<0.05)$ effect was found in subjects $>65$ years at lag 1 , with a risk increase of respiratory mortality of $6.5 \%(95 \% \mathrm{CI}$ $0.8-12.2 \%$ ) for an increased daytime noise interquartile range (IQR) of $1 \mathrm{~dB}(\mathrm{~A})$ (table 1 ). No effect was found for subjects aged $<65$ years. For those aged $>65$ years, the noise effect did not change after adjusting for PM2.5 (at lag 1) (6.1\%, 95\% CI 0.2-12.0\%) or nitrogen dioxide (at lag 1) (6.2\%, 95\% CI 0.6-11.9\%). In these multiple-exposure models adjusting for primary chemical air pollutants, an independent effect of noise was found for PM2.5 (3.3\% (95\% CI 0.3-6.2\%) for an IQR of $\left.10 \mu \mathrm{g} \cdot \mathrm{m}^{-3}\right)$ and nitrogen dioxide $(0.9 \%$ $(95 \%$ CI $0.1-1.6 \%)$ for an IQR of $\left.5 \mu \mathrm{g} \cdot \mathrm{m}^{-3}\right)$, both being statistically significant $(\mathrm{p}<0.05)$. However, to exclude a spurious relationship of this association we examined at same lag mortality in people over 65 years for circulatory causes (ICD9: 390-459), since it has also been related with noise, and more importantly for all natural causes excluding respiratory and circulatory causes (ICD9: 001-799 excluding ICD9: 460-459 and 390-459). We found a consistent noise effect for circulatory causes $(4.4 \%$ (95\% CI $0.3-8.5 \%)$ for an IQR of $1 \mathrm{db}(\mathrm{A}))$ but not other causes $(-1.3 \%(-4.7-2.0 \%)$ for an IQR of $1 \mathrm{db}(\mathrm{A}))$, even after adjusting for chemical air pollutants and effects of PM2.5 and nitrogen dioxide.

The novel finding in our study, regarding the impact of traffic noise on respiratory mortality, is consistent with those previously reported in Madrid relating traffic noise to respiratory hospital admissions [2]. Our result suggests that there are independent effects of noise and primary chemical air pollutants. This agrees with others who concluded that there is little confounding between traffic noise and air pollution [7]. The fact that noise is also related to cardiovascular mortality, as previously reported $[4,5]$, but not with other types of mortality that exclude respiratory and cardiovascular causes, as well as for both chemical air pollutants, reinforces the association between diurnal equivalent noise level and respiratory mortality. This association could appear surprising but it has also been reported in a recently published study [8], where the combined effects of chronic exposure to traffic-related air pollution and noise on the risk of skin and respiratory diseases in children and adults were studied. This suggests that the associations indicating the short-term effects of exposure to high noise levels are not spurious and are related to increased blood 
cortisol levels. This hormone is released during stress reactions, and a relationship between elevated cortisol levels and increased risks of asthma, chronic bronchitis and neurodermitis, which in turn increase with increasing traffic volume [9], has been shown.

@ERSpublications

First description of the novel association between traffic noise and respiratory mortality, independent of air pollution http://ow.ly/rFAjz

Aurelio Tobías ${ }^{1}$, Alberto Recio ${ }^{2}$, Julio Díaz ${ }^{3}$ and Cristina Linares ${ }^{4}$

${ }^{1}$ Institute of Environmental Assessment and Water Research (IDAEA), Spanish Council for Scientific Research (CSIC), Barcelona, ${ }^{2}$ Dept of Education, Comunidad de Madrid, Madrid, ${ }^{3}$ National School of Public Health, Carlos III Institute of Health, Madrid, and ${ }^{4}$ National Centre for Epidemiology, Carlos III Institute of Health, Consortium for Biomedical Research in Epidemiology and Public Health (CIBER Epidemiología y Salud Pública - CIBERESP), Madrid, Spain.

Correspondence: Aurelio Tobías, IDAEA, CSIC, C/Jordi Girona 18-26, 08031 Barcelona, Spain.

E-mail: aurelio.tobias@idaea.csic.es

Received: Oct 092013 | Accepted after revision: Dec 032012 | First published online: Jan 32014

Conflict of interest: None declared.

References

Kamp I, Davies H. Noise and health in vulnerable groups: a review. Noise Health 2013; 15: 153-159.

Tobias A, Díaz J, Saez M, et al. Use of Poisson regression and Box-Jenkins models to evaluate the short-term effects of environmental noise levels on daily emergency admissions in Madrid, Spain. Eur J Epidemiol 2001; 17: 765-771. Selander J, Nilsson ME, Bluhm G, et al. Long-term exposure to road traffic noise and myocardial infarction. Epidemiology 2009; 20: 272-279.

4 Hart JE, Rimm EB, Rexrode KM, et al. Changes in traffic exposure and the risk of incident myocardial infarction and all-cause mortality. Epidemiology 2013; 24: 734-742.

5 Maté T, Guaita R, Pichiule M. Short-term effect of fine particulate matter (PM2.5) on daily mortality due to diseases of the circulatory system in Madrid (Spain). Science Total Environment 2010; 408: 5750-5757.

$6 \mathrm{Lu} \mathrm{Y,} \mathrm{Symons} \mathrm{JM,} \mathrm{Geyh} \mathrm{AS,} \mathrm{et} \mathrm{al.} \mathrm{An} \mathrm{approach} \mathrm{to} \mathrm{checking} \mathrm{case-crossover} \mathrm{analyses} \mathrm{based} \mathrm{on} \mathrm{equivalence} \mathrm{with} \mathrm{time-}$ series methods. Epidemiology 2008; 19: 169-175.

7 Foraster M. Is it traffic-related air pollution or road traffic noise, or both? Key questions not yet settled. Int J Public Health 2013; 58: 647-648.

8 Niemann H, Maschke C. Noise effects and morbidity. WHO: LARES Final Report. www.euro.who.int/_data/ assets/pdf_file/0015/105144/WHO_Lares.pdf Date last accessed: December 12, 2013. Date last updated: May 12, 2004.

9 Ising $\mathrm{H}$, Lange-Asschenfeldt $\mathrm{H}$, Lieber GF, et al. Auswirkungen langfristiger Expositionen gegenuber Strassenverkehrs-Immissionen auf die Entwicklung von Haut- und Atemwegserkrankungen bei Kindern [Effects of long-term exposure to street traffic exhaust on the development of skin and respiratory tract diseases in children]. Schriftenr Ver Wasser Boden Lufthyg 2003; 112: 81-99.

\section{CD14/Toll-like receptors interact with bacteria and regulatory $\mathrm{T}$-cells in the development of childhood asthma}

To the Editor:

The susceptibility to asthma development in childhood is influenced by genetic as well as environmental factors, and interactions between these factors [1-3]. However, at present, their exact role is still largely undetermined. Genetic variations in the innate immune system may lead to different adaptive immune responses to bacteria and may therefore vary the development of asthma $[2,4,5]$. We performed a prospective longitudinal study in preschool children, in which we determined polymorphisms in Toll-like receptors (TLRs) and CD14, the presence of bacteria, and the proportion of regulatory T-cells (Treg) all in relation to an asthma diagnosis at 6 years of age. We hypothesise that specific genetic variants in genes that affect the innate immune system influence the response to bacteria and the recruitment of Treg in preschool children, leading to an increased likelihood of asthma at 6 years of age. 